\title{
Dialysis catheter malposition: blood gas analysis provides a clue
}

\author{
Hannah Victoria Reynolds (), ${ }^{1}$ Peter Stanley Kruger $^{2}$
}

${ }^{1}$ Intensive Care, RedcliffeCaboolture Health Service District, Redcliffe, Queensland, Australia

${ }^{2}$ Intensive Care Medicine, Princess Alexandra Hospital, Woolloongabba, Queensland, Australia

\section{Correspondence to}

Dr Hannah Victoria Reynolds; hannah.reynolds@health.qld. gov.au

Accepted 24 May 2021

\section{DESCRIPTION}

Following surgical debridement for Fournier's gangrene, a morbidly obese man $(250 \mathrm{~kg}$, Body Mass Index $87 \mathrm{~kg} / \mathrm{m}^{2}$ ) was admitted to the intensive care unit (ICU) in septic shock and multiorgan failure. His medical history included type 2 diabetes mellitus, dyslipidaemia, gastro-oesophageal reflux disease and atrial fibrillation. The severity and chronic end organ dysfunction of his comorbidities was unknown as the patient avoided doctors due to embarrassment of his weight.

On arrival to ICU, he was anuric and a decision was made to insert a dialysis catheter and start continuous renal replacement therapy (CRRT). The procedure to place an ultrasound-guided dialysis catheter into the left internal jugular vein was uncomplicated, although a routine chest X-ray (figure 1) prior to starting CRRT raised concern for arterial placement.

Transducing the pressure showed a pulsatile waveform with a pressure of $34 / 16 \mathrm{~mm} \mathrm{Hg}$ (mean $22 \mathrm{~mm} \mathrm{Hg}$ ). The central venous pressure measured from a catheter in his right internal jugular vein was $18 \mathrm{~mm} \mathrm{Hg}$ and an intra-arterial line blood pressure was $125 / 67 \mathrm{~mm} \mathrm{Hg}$. While the pressures ruled out arterial placement, concern for malposition still existed. Blood gas analysis, on $\mathrm{FiO}_{2}$ 0.5-0.55, revealed oxygen partial pressures $\left(\mathrm{PO}_{2}\right) 294 \mathrm{~mm} \mathrm{Hg}$ from the dialysis catheter, $49 \mathrm{~mm} \mathrm{Hg}$ from the central venous catheter and $68 \mathrm{mmHg}$ from the arterial line.

Given the striking differences in the $\mathrm{PO}_{2}$, catheter placement in an anomalous pulmonary vein seemed the only physiologically plausible explanation. Contrast CT scan confirmed the left upper lobe

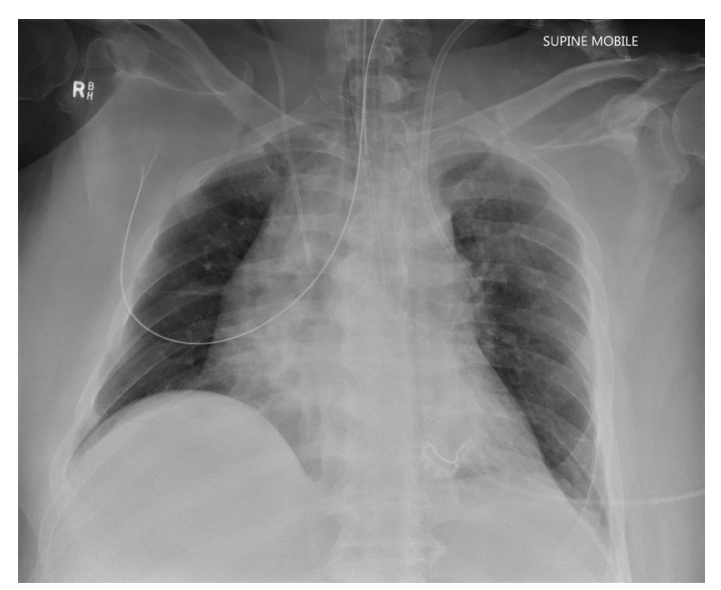

Figure 1 Chest X-ray with left-sided dialysis catheter and right-sided central venous catheter.

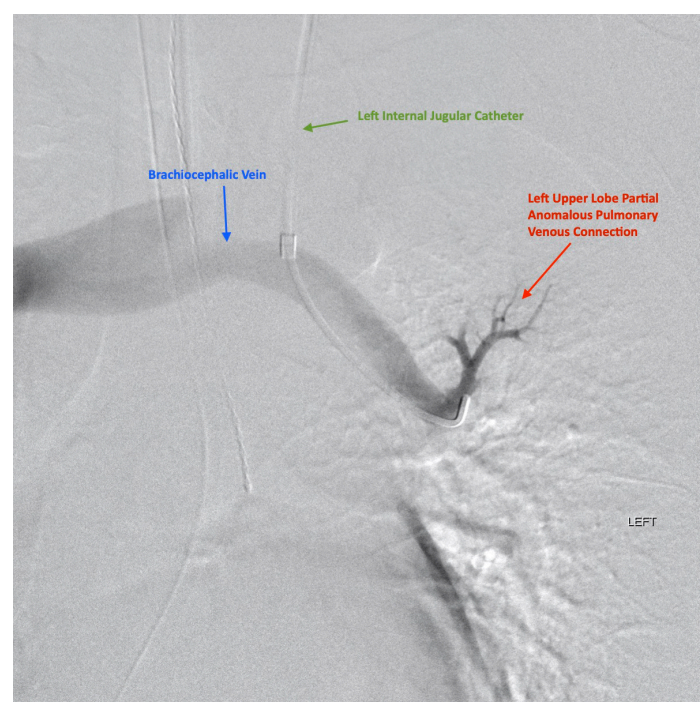

Figure 2 Contrast injected into the catheter illuminating the left upper lobe partial anomalous pulmonary venous connection.

pulmonary vein drained into the brachiocephalic vein. The patient was transferred to interventional radiology (figure 2), and the catheter was redirected to the superior vena cava/right atrium junction under fluoroscopic guidance.

With the advent of bedside ultrasound and improved training, malposition of a central venous access device has been reduced but not eliminated. ${ }^{1}$ Confirming the position (or detecting malposition) of a central venous catheter may involve a conventional chest radiograph, transducing pressures or blood gas analysis on a sample from the catheter. These steps are usually used to determine arterial versus venous placement, but on occasions, the results do not confirm either.

This case highlights the utility of blood gas analysis as part of a structured approach. Using physiological first principles that the $\mathrm{PO}_{2}$ from the dialysis catheter is approaching that seen in the alveoli $\left(\mathrm{PAO}_{2}=358 \mathrm{~mm} \mathrm{Hg}\right.$ based on alveolar gas equation and $\mathrm{PaCO}_{2}=27 \mathrm{~mm} \mathrm{Hg}$ ), the tip must lie within or in contact with the pulmonary circulation.

Abnormal pulmonary venous drainage can be either total or partial and is the result of errors during embryological development. In the literature, the incidence of partial anomalous pulmonary venous connections (PAPVC) are reported to be between $0.4 \%$ and $0.7 \% .^{2}{ }^{3}$ Although dependent on the shunt fraction, the presence of a PAPVC is usually asymptomatic and its diagnosis is usually incidental during other investigations. ${ }^{4}$ 
In the critical care setting, incidental diagnosis of a partial anomalous pulmonary venous connections during dialysis catheter insertion has been well described ${ }^{5-7}$ but the utility of blood gas analysis to provide early insight to the diagnosis less so. ${ }^{8}$ Furthermore, this case highlights the benefits of accessing interventional radiology to both clarify the exact position and relocation for patients with limited other access sites.

\section{Learning points}

- Incidental diagnosis of a partial anomalous pulmonary venous connections should be considered when the dialysis catheter takes an unusual trajectory on chest X-ray.

- Blood gas analysis is an important tool in the stepwise diagnosis of a malpositioned dialysis catheter.

- Interventional radiology is a useful resource for confirming the exact position and relocation of catheters, especially in patients with limited access sites.

Twitter Hannah Victoria Reynolds @hvreynolds

Acknowledgements The authors thank Dr Kendal Redmond.

Contributors Both authors contributed directly to the care of the patient and concept for the case report. HR contributed to the main write up and editing of the manuscript as well as obtaining images and consent from the next of kin. PSK contributed to editing the manuscript and supervision of the case report.
Funding The authors have not declared a specific grant for this research from any funding agency in the public, commercial or not-for-profit sectors.

Competing interests None declared.

Patient consent for publication Next of kin consent obtained.

Provenance and peer review Not commissioned; externally peer reviewed.

ORCID iD

Hannah Victoria Reynolds http://orcid.org/0000-0003-0219-2897

\section{REFERENCES}

1 Brass P, Hellmich M, Kolodziej L, et al. Ultrasound guidance versus anatomical landmarks for internal jugular vein catheterization. Cochrane Database Syst Rev 2015; 1:CD006962.

2 HEALEY JE. An anatomic survey of anomalous pulmonary veins: their clinical significance. J Thorac Surg 1952;23:433-44.

3 Kalke BR, Carlson RG, Ferlic RM, et al. Partial anomalous pulmonary venous connections. Am J Cardiol 1967;20:91-101.

4 Demos TC, Posniak HV, Pierce KL, et al. Venous anomalies of the thorax. Am J Roentgenol 2004;182:1139-50.

5 Pennes DR, Ellis JH. Anomalous pulmonary venous drainage of the left upper lobe shown by CT scans. Radiology 1986;159:23-4.

6 Knox S, Madruga M, Carlan SJ. Rare congenital aberrant left superior pulmonary vein discovered with central line placement in a patient with critical cardiorespiratory collapse. Case Rep Pulmonol 2017;2017:1-3.

7 Chintu MR, Chinnappa S, Bhandari S. Aberrant positioning of a central venous dialysis catheter to reveal a left-sided partial anomalous pulmonary venous connection. Vasc Health Risk Manag 2008;4:1141-3.

8 Chirinos JC, Neyra JA, Patel J, et al. Hemodialysis catheter insertion: is increased $\mathrm{PO}_{2}$ a sign of arterial cannulation? A case report. BMC Nephrol 2014;15:127-31.

Copyright 2021 BMJ Publishing Group. All rights reserved. For permission to reuse any of this content visit

https://www.bmj.com/company/products-services/rights-and-licensing/permissions/

BMJ Case Report Fellows may re-use this article for personal use and teaching without any further permission.

Become a Fellow of BMJ Case Reports today and you can:

- Submit as many cases as you like

- Enjoy fast sympathetic peer review and rapid publication of accepted articles

- Access all the published articles

- Re-use any of the published material for personal use and teaching without further permission

\section{Customer Service}

If you have any further queries about your subscription, please contact our customer services team on +44 (0) 2071111105 or via email at support@bmj.com.

Visit casereports.bmj.com for more articles like this and to become a Fellow 